\title{
Racial and ethnic differences in cognitive function among older adults in the USA
}

\author{
Carlos Díaz-Venegas ${ }^{1}$, Brian Downer ${ }^{2}$, Kenneth M. Langa ${ }^{3}$ and Rebeca Wong ${ }^{4}$ \\ ${ }^{1}$ Postdoctoral Fellow, Rehabilitation Sciences Academic Division and Research Center, The University of Texas Medical Branch, Galveston, \\ TX, USA \\ ${ }^{2}$ Postdoctoral Trainee, Sealy Center on Aging, The University of Texas Medical Branch, Galveston, TX, USA \\ ${ }^{3}$ Professor of Medicine, Division of General Medicine, University of Michigan, Ann Arbor, MI, USA \\ ${ }^{4}$ Senior Fellow, Sealy Center on Aging, Professor, Preventive Medicine \& Community Health, Director, WHO/PAHO Collaborating Center \\ on Aging and Health, The University of Texas Medical Branch, Galveston, TX, USA \\ Correspondence to: Carlos Díaz-Venegas, PhD, E-mail: cadiazve@utmb.edu
}

\begin{abstract}
Objective: Examine differences in cognition between Hispanic, non-Hispanic black (NHB), and nonHispanic white (NHW) older adults in the United States.

Data/Methods: The final sample includes 18982 participants aged 51 or older who received a modified version of the Telephone Interview for Cognitive Status during the 2010 Health and Retirement Study follow-up. Ordinary least squares will be used to examine differences in overall cognition according to race/ethnicity.

Results: Hispanics and NHB had lower cognition than NHW for all age groups (51-59, 60-69, 70-79, 80+). Hispanics had higher cognition than NHB for all age groups but these differences were all within one point. The lower cognition among NHB compared to NHW remained significant after controlling for age, gender, and education, whereas the differences in cognition between Hispanics and NHW were no longer significant after controlling for these covariates. Cognitive scores increased with greater educational attainment for all race/ethnic groups, but Hispanics exhibited the least benefit.

Discussion: Our results highlight the role of education in race/ethnic differences in cognitive function during old age. Education seems beneficial for cognition in old age for all race/ethnic groups, but Hispanics appear to receive a lower benefit compared to other race/ethnic groups. Further research is needed on the racial and ethnic differences in the pathways of the benefits of educational attainment for late-life cognitive function. Copyright (C) 2016 John Wiley \& Sons, Ltd.
\end{abstract}

Key words: cognition; older adults; race/ethnicity; HRS; USA

History: Received 22 May 2015; Accepted 03 December 2015; Published online 14 January 2016 in Wiley Online Library (wileyonlinelibrary.com)

DOI: 10.1002 /gps.4410

\section{Introduction}

Older adults often experience declines in cognition with age. These age-related changes may slow a person's ability to solve complex problems or process new information, but do not interfere with the ability to independently perform day-to-day activities (Harada et al., 2013). Social and cultural factors that accumulate through the life course play an important role in cognitive aging (Glymour and Manly, 2008), and these factors likely contribute to racial and ethnic differences in cognitive functioning at older ages (Zsembik and Peek, 2001, Sloan and Wang, 2005, Brewster et al., 2014). In general, the findings from previous research indicate that African-American and Hispanic older adults have worse cognitive functioning compared with non-Hispanic whites (NHWs), but minority older adults do not consistently exhibit significantly greater rates of cognitive decline with advancing age (Karlamangla et al., 2009, Masel and Peek, 2009, Castora-Binkley et al., 2013, Early et al., 2013). 
Hispanics experience substantial disadvantages in educational attainment compared with other racial and ethnic groups. According to the US Census (2014), 59\% of Hispanics aged 55 and over reported an educational attainment of high school or greater compared with $88 \%$ of NHWs and $80 \%$ of African Americans aged 55 and over. Despite disadvantages in educational attainment and socio-economic status, Hispanics have significantly longer life expectancy at birth compared with NHWs and non-Hispanic blacks (NHBs) (Arias, 2010). This is commonly referred to as the Hispanic paradox (Markides and Coreil, 1986), and adjusting for disparities in education has been observed to increase the gap in life expectancy between Hispanics and NHWs (Lariscy et al., 2015). Education also has a strong relationship with cognition, and disparities in education may contribute to the lower cognitive functioning among older Hispanic adults. Greater educational attainment is associated with better cognition (Alley et al., 2007) and a decreased risk for dementia (Stern et al., 1994) during old age. This may be because of highly educated older adults being able to maintain normal cognition in spite of increasing brain damage by using more efficient or alternative neural pathways (Stern, 2002).

While considerable research on race and ethnic differences in cognitive functioning has been conducted, continued research in this area is warranted because of the projected increase in the number of older minority adults, particularly Hispanic. Hispanics are one of the fastest growing minority populations in the USA with the total number expected to triple by 2050 (Jacobsen et al., 2011) and are a rapidly aging segment of the population. The number of Hispanic adults aged 65 or older increased from approximately 1.7 million in 2000 to 2.8 million in 2009 (US Census Bureau, 2011). An important limitation of prior research on cognitive aging among Hispanics is that sample populations are frequently small, drawn from clinical settings, and not nationally representative (Fitten et al., 2001, Clark et al., 2005, O’Bryant et al., 2013b, O'Bryant et al., 2013a, Fitten et al., 2014), thus limiting the generalizability of the findings.

The present study addresses this limitation by examining differences in cognitive functioning between older NHWs, African-American, and Hispanic adults using data from the 2010 wave of the Health and Retirement Study (HRS). These data were chosen because it includes an over-sampling of Hispanic older adults. We hypothesize that Hispanics will have lower scores for total cognition compared with NHWs and that these differences will be attributed to lower educational attainment among older Hispanics.

\section{Data and methods}

\section{Sample}

Data come from the HRS, a nationally representative panel of Americans older than 50 years that contains information on health, housing, disability, and cognition, among other characteristics. Baseline data collection for the HRS began in 1992 and included a combination of in-person and telephone interviews (response rate of $82 \%$ ) of individuals born between 1931 and 1941. Follow-up interviews were conducted every 2 years, and new cohorts were added approximately every 6 years (Health and Retirement Study (HRS), 2011).

In 2010, the HRS interviewed 20101 respondents but we only consider non-institutionalized respondents aged 51 or older who completed the interview themselves (i.e., without a proxy) and had a complete cognitive battery and race/ethnicity information. For the regression we further exclude 88 cases that have missing information in one or more covariates. Thus, our final sample consists of 18982 cases. The 1119 exclusions were slightly older, predominantly NHW, and had a lower total cognition score.

The HRS has oversampled African-Americans and Hispanics since its inception in 1992 at a rate of approximately 2 to 1 (HRS, 2008). However, oversampling in 2004 and 2010 was affected with the introduction of the baby boomer cohorts; thus, it reduced the sample size of these minorities (HRS, 2011). The HRS addressed this problem in 2010 by supplementing the samples of African-Americans and Hispanics in the baby boomer cohorts resulting in over 1000 additional respondents for each minority (Ofstedal and Weir, 2011).

\section{Measures}

Cognitive functioning has been assessed in the HRS by either in-person or by telephone interview using a modified version of the Telephone Interview for Cognitive Status (TICS-M) (Brandt et al., 1988). The TICS-M is comprised of 12 items with a score range of $0-35$ points. For the purposes of this study we had to use a further modified version of the TICS-M proposed by Crimmins and colleagues (2011) because participants in the HRS who were younger than 65 years of age did not receive the date or object naming items and were not asked to recall the first names of the current president and vice-president.

A summary of the cognitive measures used in this study is provided in Table 1. The total cognitive score 
Table 12010 Health and Retirement Study cognitive battery

\begin{tabular}{|c|c|c|c|}
\hline Domain & Variable & Description & Score \\
\hline Verbal memory, immediate recall & Immediate word recall & $\begin{array}{l}\text { Asking respondents to listen to a list } \\
\text { of } 10 \text { nouns and then repeat them. }\end{array}$ & $0-10$ \\
\hline Verbal memory, delayed recall & Delayed word recall & $\begin{array}{l}\text { Same as above but administered } \\
5 \text { min after completing other cognitive tests. }\end{array}$ & $0-10$ \\
\hline Working memory & Serial 7's & $\begin{array}{l}\text { Subtract } 7 \text { from } 100 \text { and continue subtracting } \\
\text { each subsequent number for five trials. }\end{array}$ & $0-5$ \\
\hline Attention and working memory & Counting backwards & $\begin{array}{l}\text { Counting backwards for } 10 \text { continuous } \\
\text { numbers beginning with } 20\end{array}$ & $\begin{array}{l}0-2 \\
2=\text { Correct on first try } \\
1=\text { Correct on second try } \\
0=\text { Incorrect on both tries }\end{array}$ \\
\hline
\end{tabular}

Source: Author's own elaboration with information from Ofstedal, Fisher, and Herzog (2005) and Fisher, Hassan, Rodgers, and Weir (2013).

of the variables presented in this table adds up to 27 points. Verbal memory was assessed by having a participant first listen to a list of 10 short, commonly used nouns, and then reciting as many words from that list as possible. Participants were also asked to recite as many words as possible from the list after a 5-min delay during which time other assessments were administered. One point was awarded for each correctly recalled word for a maximum of 20 points. Working memory was measured using the Serial 7 calculation task. This involved having a participant begin at 100 and subtract 7 for a total of 5 trials. One point was awarded for each correct subtraction for a maximum of 5 points. Finally, participants were instructed to count backwards for 10 continuous numbers as quickly as possible beginning at the number 20. Participants received 2 points if they were able to perform the task on the first attempt, 1 point if they required a second attempt, and 0 points if they did not complete the task after two attempts.

\section{Covariates}

Age: For descriptive analyses we grouped respondents into four age categories $(51-59,60-69,70-79$, and 80 or older). For regression analyses we used age as a continuous variable and we also included a quadratic term. We expect that the total cognition score will decline the more the respondent ages. Education: We included education as a continuous variable and also a squared-term. We expect that higher levels of education will result in higher levels of cognition but, at some point, the marginal benefit in the cognition score of adding one more year of education will decline. Gender: Dichotomous variable $($ women $=1$ ). Racelethnicity: Dichotomous variables measuring NHWs (reference category, hereafter NHW), non-
Hispanic blacks (hereafter NHB), other origin (Asian, Pacific Islander or Native American), and Hispanic. Respondents who refused to answer race/ethnicity were considered missing for the analysis (30 cases).

\section{Statistical analysis}

Previous research has identified gender (Halpern and LaMay, 2000, Herlitz and Yonker, 2002) and age differences (Maitland et al., 2000, Prull et al., 2000) as predictors of the total cognitive score. We present the results for the total cognition score because educational achievement might affect the scores differently for men and women as well as for each race/ethnic origin (Halpern, 2004). We then perform an ordinary least squares (OLS) regression to obtain the adjusted total cognition scores controlling for age, age squared, years of education, years of education squared, gender, and interaction terms. The procedures are conducted using STATA/SE version 13.1 (StataCorp, 2013).

\section{Results}

Table 2 presents baseline descriptive characteristics of Americans older than 50 years stratified by race/ethnicity in 2010 for the full sample and by gender. In terms of age, the sample shows that NHW are the oldest on average (67.7 years) and are 5 years older than NHB (62.1 years) and 6 years older than Hispanics (61.5 years). On average, NHW and other races have nearly 14 years of schooling, while NHB are about a year below. In contrast, Hispanics are the least educated averaging only 10 years of schooling. As for total cognition scores, women have higher score (16.0) than men (15.5) while breaking the score down by race/ethnicity shows that NHW women and NHB 


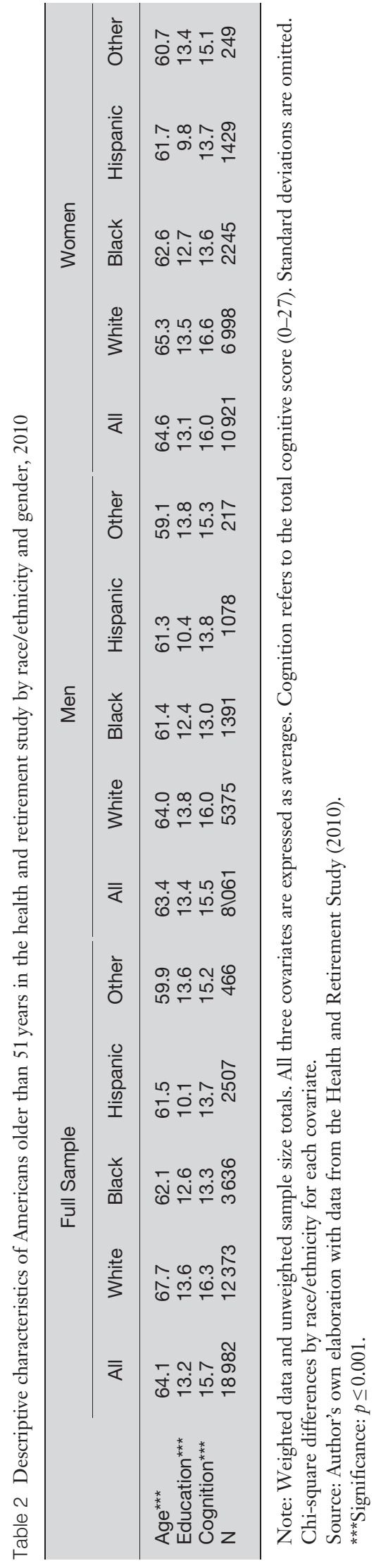

women have higher average scores than their male counterparts, while the scores for Hispanics and other races are practically even. A similar trend was observed (not shown) when analyzing specific cognitive domains so we decided to focus our analysis on the total cognition score.

To show the association between cognition and age, Table 3 includes the average cognition score stratifying by race/ethnicity and by age groups. Results suggest that cognitive scores decline as the person ages regardless of race/ethnicity. Further, total cognition scores for women of non-Hispanic races (white, black, and other) are higher or equal than the total cognition scores for their male counterparts. In contrast, only the youngest Hispanic women group (51-59years old) shows a higher total cognitive score than 51- to 59-year-old men. The rest of the Hispanic age groups show men having higher cognitive scores than women. We conducted an ancillary analysis (not shown) where we use a direct age-standardization method so our sample can have the same age structure. We take the 2010 population by age groups from the Census Brief C2010BR-03 (Howden and Meyer, 2011), calculate the population proportions, and use them as standardizing weights. The results are similar to the ones presented on Table 3.

Table 4 shows the OLS results estimating the 2010 total cognition score. Model 1 controls for age, age squared, and race/ethnicity. Overall, age is significant and shows the expected direction. In the main effect of race/ethnicity, NHB have a total cognitive score 3.29 points lower than NHW while Hispanics and other races have 3.23 and 1.68 points lower than NHW, respectively. Model 2 adds years of education and years of education squared. Both age and years of education remained significant. Model 3 adds the interaction terms between race/ethnicity and age, and race/ethnicity and gender. The graphic representation of the predicted total cognition score from Model 3 by race/ethnicity and age keeping the remaining covariates at their mean is shown on Figure 1. With the inclusion of interaction terms, ${ }^{1} \mathrm{NHW}$ show a decline in the total cognition score of 0.11 points for each additional year of age, which is higher than NHB (0.07 points), other races (0.05 points), and Hispanics (0.05 points).

Model 4 adds the interaction terms between race/ethnicity and years of education. Overall, all race/ethnic groups seem to benefit from more years

\footnotetext{
${ }^{1}$ The calculation of these numbers represents the marginal benefit of each specific variable keeping the rest at their means and was obtained by using the margins command in Stata after performing each OLS regression.
} 
Table 3 Average total cognition score of Americans older than 51 years in the health and retirement study by race/ethnicity and age group, 2010

\begin{tabular}{|c|c|c|c|c|c|c|c|c|c|}
\hline \multicolumn{5}{|c|}{ Total cognition score (0-27) } & \multicolumn{5}{|c|}{ Cell sizes } \\
\hline All & White & Black & Hispanic & Other & ALL & White & Black & Hispanic & Other \\
\hline $51-59$ & 17.4 & 14.2 & 14.3 & 15.9 & $51-59$ & 3426 & 1780 & 1270 & 272 \\
\hline 60-69 & 16.9 & 13.5 & 13.9 & 14.9 & $60-69$ & 3339 & 907 & 607 & 101 \\
\hline 70-79 & 15.3 & 11.7 & 12.5 & 14.3 & 70-79 & 3614 & 749 & 508 & 71 \\
\hline $80+$ & 12.6 & 9.3 & 9.2 & 11.1 & $80+$ & 2036 & 221 & 138 & 31 \\
\hline \multicolumn{5}{|c|}{ Total cognition score $(0-27)$} & \multicolumn{5}{|c|}{ Cell sizes } \\
\hline MEN & White & Black & Hispanic & Other & MEN & White & Black & Hispanic & Other \\
\hline $51-59$ & 16.9 & 13.6 & 13.9 & 15.7 & $51-59$ & 1569 & 716 & 563 & 131 \\
\hline 60-69 & 16.4 & 13.1 & 14.4 & 14.9 & $60-69$ & 1375 & 327 & 254 & 47 \\
\hline 70-79 & 14.8 & 11.0 & 12.9 & 15.7 & 70-79 & 1592 & 285 & 216 & 29 \\
\hline $80+$ & 12.4 & 9.6 & 9.3 & 11.7 & $80+$ & 862 & 73 & 53 & 15 \\
\hline \multicolumn{5}{|c|}{ Total cognition score $(0-27)$} & \multicolumn{5}{|c|}{ Cell sizes } \\
\hline WOMEN & White & Black & Hispanic & Other & WOMEN & White & Black & Hispanic & Other \\
\hline $51-59$ & 17.8 & 14.6 & 14.5 & 16.0 & $51-59$ & 1857 & 1064 & 707 & 141 \\
\hline 60-69 & 17.4 & 13.8 & 13.6 & 14.9 & 60-69 & 1964 & 580 & 353 & 54 \\
\hline 70-79 & 15.6 & 12.1 & 12.2 & 13.3 & 70-79 & 2022 & 464 & 292 & 42 \\
\hline $80+$ & 12.7 & 9.2 & 9.2 & 10.5 & $80+$ & 1174 & 148 & 85 & 16 \\
\hline
\end{tabular}

Note: Weighted data and unweighted sample size totals. Standard deviations are omitted.

Source: Author's own elaboration with data from the Health and Retirement Study (2010).

of education. The main effect of race/ethnicity is reduced for Hispanics compared with Models 1 and 2, and the difference between NHW and Hispanics for cognition in Model 4 was no longer statistically significant (coefficient $=-0.52$ ). However, the race/ ethnic differences in Model 4 increased for NHB (coefficient $=-5.28$ ) and other races (coefficient $=-2.93$ ). Additionally, being female represents a marginal benefit of 1.03 points for NHW, 0.57 points for NHB, 0.20 points for Hispanics, and 0.15 points for other races.

The effect of education by race/ethnicity, keeping age fixed at 60 and other covariates at their means, is presented on Figure 2. An interesting observation occurs at zero years of education. Both NHW and Hispanics appear to have a predicted cognitive score slightly over 10 points but the gap between them increases as each gain more years of education. All races/ethnic groups are benefitting from achieving more education but NHB show the largest gains on the total cognition score ( 0.67 points per year of education achieved) followed by other races with 0.61 points and then by NHW with 0.54 points. In contrast, Hispanics also benefit from more years of education but they show the smallest gains with only 0.35 points per year.

\section{Discussion and conclusions}

This paper aimed to expand the existing literature on cognitive functioning of older adults, by examining the association of cognition and race/ethnicity in the USA, paying particular attention to Hispanics. Key results show that lower cognitive functioning among Hispanic older adults compared with NHW is due largely in part to differences in educational attainment. Also, Hispanics are, on average, younger and with fewer years of schooling than NHW and NHB. In terms of cognitive functioning, women have higher average scores than their male counterparts, but the gender differences are greater for NHW and NHB compared with Hispanics and other races. Overall, OLS results are consistent with previous research that shows that being older is associated with lower total cognition scores while being more educated is associated with higher total cognition scores. Also, our finding that females had higher cognitive functioning compared with men is consistent with previous studies (McArdle et al., 2007, Downer et al., 2015), but continued research is necessary to understand why gender differences in cognition may vary according to race/ethnicity.

Our results highlight the importance of education and its undeniable association with cognition. Educational attainment is achieved early in life, but it has consequences that affect an individual during adulthood (e.g., occupation and income) and late life (e.g., health and cognitive impairment) (Haan et al., 2011). Results on Table 4 seem to indicate that an increase in the quantity of education of older adults in the USA represents higher total cognition scores regardless of 
Table 4 Ordinary least squares coefficients of the 2010 total cognition score of respondents older than 51 years by race/ethnicity

\begin{tabular}{|c|c|c|c|c|c|}
\hline Variables & $\begin{array}{l}\text { Model } 1 \text { coefficient } \\
\text { (robust SE) }\end{array}$ & $\begin{array}{l}\text { Model } 2 \text { coefficient } \\
\text { (robust SE) }\end{array}$ & $\begin{array}{l}\text { Model } 3 \text { coefficient } \\
\text { (robust SE) }\end{array}$ & $\begin{array}{l}\text { Model } 4 \text { coefficient } \\
\text { (robust SE) }\end{array}$ & $\begin{array}{l}\text { Model } 4 \\
95 \% \mathrm{Cl}\end{array}$ \\
\hline \multicolumn{6}{|c|}{ Sociodemographic characteristics } \\
\hline Age & $0.46^{\star \star \star}(0.03)$ & $0.49^{\star \star \star}(0.03)$ & $0.47^{\star \star \star}(0.03)$ & $0.47^{\star \star \star}(0.03)$ & $0.41-0.53$ \\
\hline Age squared & $-0.004^{\star \star \star}(0.00)$ & $-0.004^{\star \star \star}(0.00)$ & $-0.004^{\star \star \star}(0.00)$ & $-0.004^{\star \star \star}(0.00)$ & $-0.005--0.04$ \\
\hline Female & $0.68^{\star \star \star}(0.05)$ & $0.82^{\star \star \star}(0.05)$ & $1.03^{\star \star \star}(0.06)$ & $1.02^{\star \star \star}(0.06)$ & $0.89-1.14$ \\
\hline Years of education & & $0.20^{\star \star \star}(0.04)$ & $0.21^{\star \star \star}(0.04)$ & $0.39^{\star \star \star}(0.06)$ & $0.26-0.51$ \\
\hline Years of education squared & & $0.01^{\star \star \star}(0.001)$ & $0.01^{\star \star \star}(0.001)$ & $0.006^{*}(0.02)$ & $0.001-0.01$ \\
\hline \multicolumn{6}{|l|}{$\begin{array}{l}\text { Race/ethnicity (Ref:: } \\
\text { non-Hispanic whites) }\end{array}$} \\
\hline Non-Hispanic blacks (NHB) & $-3.29^{\star \star \star}(0.08)$ & $-2.70^{\star \star \star}(0.07)$ & $-2.68^{\star \star \star}(0.47)$ & $-5.28^{\star \star \star}(0.70)$ & $-6.65--3.91$ \\
\hline Other races & $-1.68^{\star * \star}(0.19)$ & $-1.63^{\star \star \star}(0.18)$ & $-1.81^{\star \star \star}(1.09)$ & $-2.93^{\star}(1.42)$ & $-5.72--0.15$ \\
\hline Hispanics & $-3.23^{\star \star \star}(0.09)$ & $-1.42^{\star \star \star}(0.09)$ & $-2.51^{\star \star \star}(0.55)$ & $-0.52(0.71)$ & $-1.91-0.87$ \\
\hline \multicolumn{6}{|l|}{ Interaction terms } \\
\hline $\mathrm{NHB} *$ Age & & & $0.04(0.007)$ & $0.02^{*}(0.01)$ & $0.002-0.03$ \\
\hline NHB * Gender & & & $-0.46^{\star \star}(0.15)$ & $-0.51^{\star \star \star}(0.15)$ & $-0.79--0.22$ \\
\hline $\begin{array}{l}\mathrm{NHB} * \text { Years of } \\
\text { education }\end{array}$ & & & & $0.14^{\star \star \star}(0.29)$ & $0.09-0.20$ \\
\hline Other races * Age & & & $0.01(0.02)$ & $0.02(0.02)$ & $-0.02-0.05$ \\
\hline Other races * Gender & & & $-0.88^{\star \star}(0.34)$ & $-0.84^{*}(0.34)$ & $-1.51--0.17$ \\
\hline $\begin{array}{l}\text { Other races * Years of } \\
\text { education }\end{array}$ & & & & $0.06(0.06)$ & $-0.05-0.17$ \\
\hline Hispanics * Age & & & $0.03^{\star \star}(0.09)$ & $0.02^{*}(0.01)$ & $0.001-0.04$ \\
\hline Hispanics * Gender & & & $-0.84^{\star \star \star}(0.17)$ & $-0.85^{\star \star \star}(0.17)$ & $-1.18--0.52$ \\
\hline $\begin{array}{l}\text { Hispanics * Years of } \\
\text { education }\end{array}$ & & & & $-0.14^{\star \star \star}(0.03)$ & $-0.20--0.08$ \\
\hline Constant & $4.87^{\star \star \star}(1.09)$ & $-2.08^{\star}(1.06)$ & $-1.58(1.08)$ & $-2.48^{\star}(1.15)$ & $-4.73--0.22$ \\
\hline Unweighted $N$ & 18,982 & & & & \\
\hline$R^{2}$ & 0.21 & 0.30 & 0.31 & 0.32 & - \\
\hline
\end{tabular}

Note: Robust standard errors appear in parentheses. Because of space, only confidence intervals for the full model are presented.

Source: Author's own elaboration with data from the Health and Retirement Study (2010).

${ }^{*} p \leq 0.05$.

${ }^{* *} p \leq 0.01$.

${ }^{* * *} p \leq 0.001$

race/ethnicity, which is consistent with previous literature (Sheffield and Peek, 2011). However, NHW and Hispanics had similar cognitive functioning at zero years of education, but Hispanics experienced less of a benefit of greater educational attainment compared with NHW (Figure 2). This, along with the non-significant differences in total cognition between NHW and Hispanics presented in Table 4 (Model 4), provides evidence that differences in educational attainment cause differences in cognitive functioning between NHW and Hispanic older adults.

As shown on Figure 1, differences in the initial level of cognition (intercept) have a greater impact on race/ethnicity differences in cognition during old age than changes in cognition with age (slope). Previous research has found similar results with $\mathrm{NHB}$, other non-Hispanic races, and Hispanics being below NHW in total cognitive score (Zahodne et al., 2011, Marsiske et al., 2013), indicating that other factors (i.e., quality of education or literacy) might be also affecting the level and slope of cognitive scores for each race/ethnic group. Similarly, fixing age at 60 (Figure 2) shows that while more education seems to bring higher cognitive scores for all race and ethnic groups, Hispanics do not appear to gain as great of an advantage as indicated by the by flatter slope compared with the other race and ethnic groups. The limited benefit of educational attainment for Hispanics may be because of racial and ethnic differences in educational quality, especially for Mexicans (the majority of Hispanics in our sample) who received their education in Mexico before migrating to the USA. This is supported by the trend for educational attainment on cognition reported by Al Hazzouri and colleagues (2011), where they observed greater cognitive benefits of education for US-born individuals of Mexican origin than for Mexican-born individuals living in Mexico. Prior research has demonstrated that the mortality advantage for Hispanics increases after adjusting for educational attainment (Lariscy et al., 2015) Thus, our finding that Hispanics do not experience as great of a benefit from 


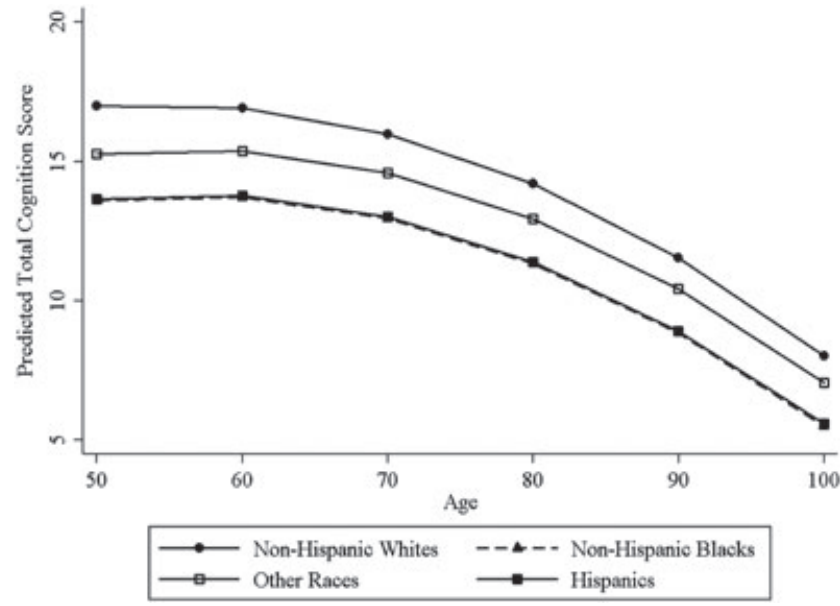

Note: Controlling for age, age squared, gender, years of education, years of education squared, and interaction terms. All covariates are expressed at their means. The line for non-Hispanic blacks (dashed with triangles) virtually overlaps the line for Hispanics (solid with squares).

Source: Author's own elaboration with data from the Health and Retirement Study (2010).

Figure 1 Predicted total cognition score of respondents older than 51 years by race/ethnicity.

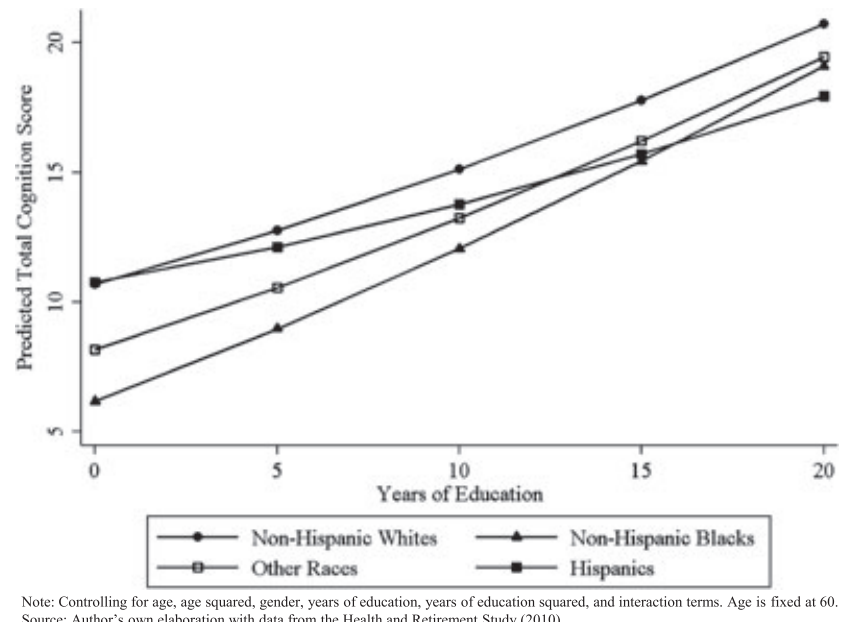
Note: Controlling for age, age squared, gender, years of education, years of education squar
Source: Author's own elaboration with data from the Health and Retirement Study (2010).

Figure 2 Predicted total cognition score of respondents aged 60 by years of education and race/ethnicity.

education on cognitive functioning is inconsistent with the Hispanic Paradox.

We observed that NHW were significantly older than the other race/ethnic groups, but had significantly higher total cognition compared with Hispanics, NHB, and other races, and that these differences persisted with age. The conflicting findings for average age and cognition suggest that disparities in cognitive functioning may increase as the US population ages. Our results are consistent with those reported by Skirbekk and colleagues (2012), who observed that despite having significantly younger chronological age, older adults in Mexico and other developing countries had significantly lower cognition compared with older adults in the USA. The authors also proposed that differences in cognition may be because of poor living conditions in low-income and middle-income countries, which might be a contributing factor in the cognitive disparities observed in this study.

Cognitive functioning of older Hispanics may also be influenced by factors related to their level of acculturation, including how long they have lived in the USA, if they were foreign-born or native-born, and English proficiency. Prior research indicates that highly acculturated foreign-born Hispanics tend to process and respond to cognitive stimuli presented in English better than low acculturated foreign-born Hispanics (Beniflah et al., 2014). Furthermore, lifelong bilingualism may contribute to preserve cognitive functioning and a more efficient neural processing with age because of the cognitive demands placed on switching between languages (Gold et al., 2013). Additional research is necessary to determine if differences in acculturation contribute to variations in cognition among Hispanic older adults.

Our paper comes with limitations. First, our sample does not consider respondents who answered the cognitive battery through a proxy. These respondents will exhibit higher cognitive impairment, thus biasing our sample towards better total cognition scores. Second, the HRS uses a mix of in-person and telephone interviews to conduct the cognitive portion of the questionnaire. For this reason, the study is unable to include non-verbal tasks that challenge the respondents to use their visual perception and/or construction skills (Fisher et al., 2013). Finally, the relationship between cognition and race/ethnicity is affected by a myriad of conditions that vary across communities and even individuals. Educational attainment, age, and gender have been consistently linked to cognitive functioning (Hofer and Alwin, 2008, Jefferson et al., 2011), but factors that are reflected in the different life courses experienced by each race/ethnic group such as income, assets, health insurance, chronic conditions, depression, employment, and among others could potentially alter the overall cognitive functioning by race/ethnicity, and future studies should consider inclusion of such confounders (Adams et al., 2003).

Cognitive functioning varies over time, and cognitive scores are different for each race/ethnic group in the USA. Regardless of the magnitude of these changes, future research should expand the analysis of the interaction between cognitive functioning and race/ethnicity so researchers can fully understand the key components that might alter this relationship and evaluate possible public policies that will reduce the disparities among race/ethnic groups. In addition, 
while cross-section studies have shown a relationship between cognition and race/ethnicity (Zsembik and Peek, 2001, Sloan and Wang, 2005), future research should expand this type of analysis in order to incorporate more data and present the trajectories of cognitive decline for each race/ethnicity.

\section{Conflict of interest}

None declared.

\section{Key points}

- We use a nationally representative study of older adults in the USA with an oversample of Hispanics to examine differences in cognitive functioning by race/ethnicity.

- Women have higher total cognitive scores compared with men except for Hispanics.

- Cognitive scores increased with greater educational attainment, but Hispanics showed the least benefit.

- Educational attainment is achieved early in life but it affects an individual during the rest of his/her life cycle.

\section{Acknowledgements}

This work was supported in part by the National Institute on Aging at the National Institutes of Health (grants R01 AG018016 and 5T32 AG000270-16) and by the National Institute on Disability and Rehabilitation Research (postdoctoral training grant H133P110012).

\section{References}

Adams P, Hurd MD, McFadden DL, Merrill A, Ribeiro T. 2003. Healthy, wealthy, and wise? Tests for direct causal paths between health and socioeconomic status. J Econom 112: 3-56.

Al Hazzouri AZ, Haan MN, Galea S, Aiello AE. 2011. Life-course exposure to early socioeconomic environment, education in relation to late-life cognitive function among older Mexicans and Mexican Americans. J Aging Health 23: $1027-1049$.

Alley D, Suthers K, Crimmins EM. 2007. Education and cognitive decline in older Americans: results from the AHEAD sample. Res Aging 29: 73-94.

Arias E. 2010. United States Life Tables by Hispanic Origin. National Center for Health Statistics on: Washington, DC.

Dr. Beniflah J, Chatterjee S, Curtis K. 2014. Bilingual memory: the impact of acculturation on the cognitive structure of foreign-born Hispanics. J Brand Strategy 3: 261-277.

Brandt J, Spencer M, Folstein MF. 1988. The telephone interview for cognitive status. Neuropsychiatry Neuropsychol Behav Neurol 1: 111-117.

Brewster PWH, Melrose RJ, Marquine MJ, et al. 2014. Life experience and demographic influences on cognitive function in older adults. Neuropsychology 28: $846-858$.
Castora-Binkley M, Peronto CL, Edwards JD, Small BJ. 2013. A Longitudinal Analysis of the Influence of Race on Cognitive Performance. J Gerontol B Psychol Sci Soc Sci 70: $512-518$.

Clark CM, DeCarli C, Mungas D, et al. 2005. Earlier onset of Alzheimer disease symptoms in Latino individuals compared with Anglo individuals. Arch Neurol 62: 774-778.

Crimmins EM, Kim JK, Langa KM, Weir DR. 2011. Assessment of cognition using surveys and neuropsychological assessment: the health and retirement study and the aging, demographics, and memory study. J Gerontol B Psychol Sci Soc Sci 66B: i162-i171.

Downer B, Fardo DW, Schmitt FA. 2015. A summary score for the Framingham Heart Study neuropsychological battery. J Aging Health 27: 1199-1222.

Early DR, Widaman KF, Harvey D, et al. 2013. Demographic predictors of cognitive change in ethnically diverse older persons. Psychol Aging 28: 633-645.

Fisher GG, Hassan H, Rodgers WL, Weir DR. 2013. Health and Retirement Study Imputation of Cognitive Functioning Measures: 1992-2010 (Final Release Version) Data Description. University of Michigan: Ann Arbor, MI.

Fitten LJ, Ortiz F, Fairbanks L, et al. 2014. Younger age of dementia diagnosis in a Hispanic population in Southern California. Int J Geriatr Psychiatry 29: 586-593.

Fitten LJ, Ortiz F, Ponton M. 2001. Frequency of Alzheimer's disease and other dementias in a community outreach sample of Hispanics. J Am Geriatr Soc 49: 1301-1308.

Glymour MM, Manly JJ. 2008. Lifecourse social conditions and racial and ethnic patterns of cognitive aging. Neuropsychol Rev 18: 223-254.

Gold BT, Kim C, Johnson NF, Kryscio RJ, Smith CD. 2013. Lifelong bilingualism maintains neural efficiency for cognitive control in aging. J Neurosci 33: 387-396.

Haan MN, Al-Hazzouri AZ, Aiello AE. 2011. Life-span socioeconomic trajectory, nativity, and cognitive aging in Mexican Americans: the Sacramento Area Latino study on aging. J Gerontol B Psychol Sci Soc Sci 66B: i102-il10.

Halpern DF. 2004. A cognitive-process taxonomy for sex differences in cognitive abilities. Curr Dir Psychol Sci 13: 135-139.

Halpern DF, LaMay ML. 2000. The smarter sex: a critical review of sex differences in intelligence. Educ Psychol Rev 12: 229-246.

Harada CN, Natelson Love MC, Triebel KL. 2013. Normal cognitive aging. Clin Geriatr Med 29: 737-752.

Health and Retirement Study. 2008. Survey design. Available: http://hrsonline.isr. umich.edu/sitedocs/surveydesign.pdf [Accessed April 2015].

Health and Retirement Study. 2010. 2010 Core Final, Version 1.0, Data Description and Usage. University of Michigan: Ann Arbor, MI.

Health and Retirement Study. 2011. Sample sizes and response rates. Available: http://hrsonline.isr.umich.edu/sitedocs/sampleresponse.pdf [Accessed April 2015].

Herlitz A, Yonker JE. 2002. Sex differences in episodic memory: the influence of intelligence. J Clin Exp Neuropsychol 24: 107-114.

Hofer SM, Alwin DF. 2008. Handbook of Cognitive Aging: Interdisciplinary Perspectives. Los Angeles, CA: Sage.

Howden LM, Meyer JA. 2011. Age and sex composition: 2010. (C2010BR-03). Washington, D.C.: U.S. Census Bureau. Retrieved from https://www.census. gov/prod/cen2010/briefs/c2010br-03.pdf on Oct. 2015.

Jacobsen LA, Kent M, Lee M, Mather M. 2011. America's aging population. Popul Bull 66: 1-16.

Jefferson AL, Gibbons LE, Rentz DM, et al. 2011. A life course model of cognitive activities, socioeconomic status, education, reading ability, and cognition. J Am Geriatr Soc 59: 1403-1411.

Karlamangla AS, Miller-Martinez D, Aneshensel CS, et al. 2009. Trajectories of cognitive function in late life in the United States: demographic and socioeconomic predictors. Am J Epidemiol 170: 331-342.

Lariscy JT, Hummer RA, Hayward MD. 2015. Hispanic older adult mortality in the United States: new estimates and an assessment of factors shaping the hispanic paradox. Demography 52: 1-14.

Maitland SB, Intrieri RC, Schaie WK, Willis SL. 2000. Gender differences and changes in cognitive abilities across the adult life span. Aging Neuropsychol C: A Journal on Normal and Dysfunctional Development 7: 32-53.

Markides KS, Coreil J. 1986. The Health of Hispanics in the Southwestern United States: an epidemiologic paradox. Public Health Rep 101: 253-265.

Marsiske M, Dzierzewski JM, Thomas KR, et al. 2013. Race-related disparities in 5 -year cognitive level and change in untrained active participants. J Aging Health 25: 103S-127S.

Masel MC, Peek MK. 2009. Ethnic differences in cognitive function over time. Ann Epidemiol 19: 778-783.

McArdle JJ, Fisher GG, Kadlec KM. 2007. Latent variable analysis of age trends of cognition in the health and retirement study, 1992-2004. Psychol Aging 22: 525-545.

O’Bryant SE, Johnson L, Balldin V, et al. 2013a. Characterization of Mexican Americans with mild cognitive impairment and Alzheimer's disease. J Alzheimer's Dis: JAD 33: 373-9.

O'Bryant SE, Johnson L, Reisch J, et al. 2013b. Risk factors for mild cognitive impairment among Mexican Americans. Alzheimer's Dement: The Journal of the Alzheimer's Association 9: 622-631. 
Ofstedal MB, Fisher GG, Herzog AR. 2005. Documentation of Cognitive Functioning Measures in the Health and Retirement Study. University of Michigan: Ann Arbor, MI. Ofstedal MB, Weir DR. 2011. The recruitment and retention of minority participants in the health and retirement study. Gerontologist 51: S8-S20.

Prull MW, Gabrieli JDE, Bunge SA. 2000. Age-related changes in memory: a cognitive neuroscience perspective. In The Handbook of Aging and Cognition, Craik FIM, Salthouse TA (eds.)(eds.). 2nd. edn.Lawrence Erlbaum Associates Publishers: Mahwah, NJ.

Sheffield KM, Peek MK. 2011. Changes in the prevalence of cognitive impairment among older Americans, 1993-2004: overall trends and differences by race/ethnicity. Am J Epidemiol 174: 274-283.

Skirbekk V, Loichinger E, Weber D. 2012. Variation in cognitive functioning as a refined approach to comparing aging across countries. Proc Natl Acad Sci U S A 109: $770-774$.

Sloan FA, Wang JS. 2005. Disparities among older adults in measures of cognitive function by race or ethnicity. J Gerontol B Psychol Sci Soc Sci 60: P242-P250.

StataCorp. 2013. Stata Statistical Software: Release 13. StataCorp LP: College Station, TX.
Stern Y. 2002. What is cognitive reserve? theory and research application of the reserve concept. J Int Neuropsychol Soc 8: 448-460.

Stern Y, Gurland B, Tatemichi TK, et al. 1994. Influence of education and occupation on the incidence of Alzheimer's disease. JAMA-J Am Med Assoc 271: 1004-1010.

U.S. Census Bureau. 2011. Table 9: Resident Population by Race, Hispanic Origin, and Age: 2000 and 2009. Washington D.C.: U.S. Census Bureau. Retrieved from http://www.census.gov/prod/2011pubs/11statab/pop.pdf on Oct. 2015.

U.S. Census Bureau. 2014. Table 1: Educational Attainment of the Population 18 year, and over, by age, sex, race, and Hispanic Origin: 2014. Current Population Survey 2014: Annual Social and Economic Supplement. Retrieved from http://www.census.gov/hhes/socdemo/education/data/cps/2014/tables.html on Oct. 2015.

Zahodne LB, Glymour MM, Sparks C, et al. 2011. Educational attainment of the population 18 years and over, by age, sex, race: 12 year evidence from the Victoria longitudinal study. J Int Neuropsychol Soc 17: 1039-1046.

Zsembik BA, Peek MK. 2001. Race differences in cognitive functioning among older adults. J Gerontol B Psychol Sci Soc Sci 56: S266-S274. 